\title{
Secondary Molecular Ion Emission In Binary Projectile-Surface Collisions
}

\author{
T. Jalowy ${ }^{1}$, R. Neugebauer ${ }^{1}$, L. S. Farenzena ${ }^{2}$, V. M. Collado ${ }^{2}$, \\ H. Schmidt-Böcking ${ }^{1}$, E. F. da Silveira ${ }^{2}$ and K. O. Groeneveld ${ }^{1}$
}

\author{
1-Institut für Kernphysik der J.W.Goethe Universität, August-Euler-Str.6, \\ D-60486 Frankfurt am Main, Germany \\ 2-Pontificia Universidade Católica, Departamento de Física \\ CP 38071, Rio de Janeiro 22452-970, Brazil
}

\begin{abstract}
Secondary molecular ions, emitted from a LiF target bombarded by a MeV argon beam, are analyzed by a XY-TOF detection system. This new method allows, for each emitted ion, simultaneous measurement of its time-of flight (TOF) and its impact coordinates (XY) on the detector surface, after acceleration by a homogenous electric field. Angular distributions and initial velocities for atomic $\left(\mathrm{H}^{+}, \mathrm{Li}^{+}, \mathrm{C}^{+}\right)$and for molecular $\left(\mathrm{H}_{\mathrm{n}}^{+}, \mathrm{C}_{\mathrm{m}} \mathrm{H}_{\mathrm{n}}^{+}\right)$ions are determined. The analysis reveals different emission processes, among them a unexpected emission of fast molecular ions from binary collisions.
\end{abstract}

\section{INTRODUCTION}

Surface analysis using ion beams can be performed by scattering or by desorption techniques. In the first case, the scattered projectile is the detected particle and the method is usually referred to as Low Energy Ion Scattering (LEIS), Ion Scattering Spectroscopy (ISS) or Rutherford Backscattering (RBS), depending on the projectile energy. The advantage of such analyses is their ability to determine both composition and structural information of the surface [1]. In the second case, surface atoms or molecules are detected. The names of the related methods have some divergence in the literature, but it is reasonable to call the process "desorption" when atoms or molecules are only emitted in the eV range; Secondary Ion Mass Spectrometry (SIMS) is specific for projectile impact in the $\mathrm{keV}$ range, while Elastic Recoil Detection Analysis (ERDA) is employed when both projectile and recoiled particle have energies in the hundreds of $\mathrm{keV}$ or MeV range.

Since molecular bonds are generally destroyed in energetic collisions, only charged or neutral atomic species are expected in ERDA experiments. For the same reason, charged or neutral molecular species are common, or even dominant, in $\mathrm{eV}$ secondary particle emission processes. It is then understandable that molecular species are not emitted from the center region of the projectile impact, but rather from relatively distant peripheral sites, in which case the transferred energy density is low enough to maintain molecular bonding and thus to allow desorption of molecules. In other words, molecular ion emission proceeds via collective processes (e.g., linear cascade, pressure pulses and electron multi-hits), lowering the energy and momentum transferred from the projectile to the ejectile [2-7].

In this work, we present experimental results which show that molecular emission can occur under energetic binary collision between projectiles and surface molecules. This process is observed under appropriate conditions which are described in the next sections. The current method opens a new approach to analyze the interaction between the projectile and surface molecules. 


\section{EXPERIMENT}

The experimental set-up allows the measurement of the 3-dimensional vector velocity and the angle distributions of secondary ions emitted from surfaces under particle impact. The used mass spectrometer is a time-of-flight (TOF) type, improved with an imaging system to determine the impact positions of each emitted secondary ion. This system is based on a 2dimensional position-sensitive $(\mathrm{XY})$ detector. The $\mathrm{XZ}$ scattering plane is defined by the beam trajectory and by the spectrometer symmetry axis (the $Z$ axis, perpendicular to the target surface), the incidence projectile impact angle $\theta_{\mathrm{p}}$ is formed by these two directions. The system has especular symmetry with respect to $\mathrm{XZ}$ plane, i.e., to the $\mathrm{y}=0$ co-ordinate.

To improve mass resolution and preserve a large radial energy acceptance, the spectrometer described in ref. [8] was modified in order to have a short extraction region $(0.77 \mathrm{~cm}$ with a field of $3.8 \mathrm{kV} / \mathrm{cm})$ and a longer drift region $(8.34 \mathrm{~cm})$. A thin $\mathrm{LiF}$ film $(200 \AA)$, prepared by evaporation in vacuum, was bombarded by $\mathrm{Ar}^{0}$ incident beam $\left(25 \mathrm{keV} / \mathrm{u}, \theta_{\mathrm{p}}=37^{\circ}\right)$ at $3-5 \times 10^{3}$ projectiles per second.

\section{RESULTS}

Fig. 1 shows a TOF spectrum of positive secondary ions obtained under these conditions. Besides the ${ }^{6} \mathrm{Li}^{+}$, ${ }^{7} \mathrm{Li}^{+}$and $\mathrm{Li}_{2}{ }^{+}$TOF peaks, corresponding to the bulk target material, it is observed $\mathrm{H}_{n}{ }^{+}$and $\mathrm{C}_{\mathrm{n}} \mathrm{H}_{\mathrm{m}}{ }^{+}$peaks due to the surface contaminants $\mathrm{H}_{2}, \mathrm{H}_{2} 0, \mathrm{~N}_{2}$ and hydrocarbons $\mathrm{C}_{\mathrm{x}} \mathrm{H}_{\mathrm{y}}$ at the current high vacuum conditions $\left(5 \times 10^{-7} \mathrm{mbar}\right)$. The peaks of the atomic species $\mathrm{H}^{+}, \mathrm{Li}^{+}$and $\mathrm{C}^{+}$are broad (>10 ns), indicating that these secondary ions are emitted with relatively high emission velocities. On the other hand, the molecular peaks of $\mathrm{H}_{2}{ }^{+}, \mathrm{H}_{3}{ }^{+}, \mathrm{Li}_{2}{ }^{+}$and $\mathrm{CH}_{3}{ }^{+}$are narrow (few ns), which is a clear sign of their low initial velocity. Surprisingly, the molecular $\mathrm{CH}^{+}$and $\mathrm{CH}_{2}^{+}$ exhibit a broad, step shaped appearance. The $\mathrm{N}^{+} / \mathrm{CH}_{2}{ }^{+}$ peak overlaps a narrower peak of $\mathrm{Li}_{2}{ }^{+}$.

The XY-TOF detection system provides a clear explanation for the observed peak shapes. The same data as Fig. 1 are presented in Fig. 2a as a XT-plot, i.e., event-by-event, the measured $\mathrm{x}$ impact co-ordinate plotted as a function of the TOF. Projectiles move from positive to negative values of $\mathrm{x}$. From this new XT plot, one sees of the target ${ }^{6} \mathrm{Li}^{+}$and ${ }^{7} \mathrm{Li}^{+}$ distributions are very broad, in contrast with 3 sharp, needle-shaped lines, visible at negative $x$ values. These lines are generated by the adsorbate constituents of mass $\mathrm{m}=12 \mathrm{u}\left(\mathrm{C}^{+}\right), \mathrm{m}=13 \mathrm{u}\left(\mathrm{CH}^{+}\right)$and $14 \mathrm{u}\left(\mathrm{CH}_{2}{ }^{+}\right.$, $\mathrm{N}^{+}$.

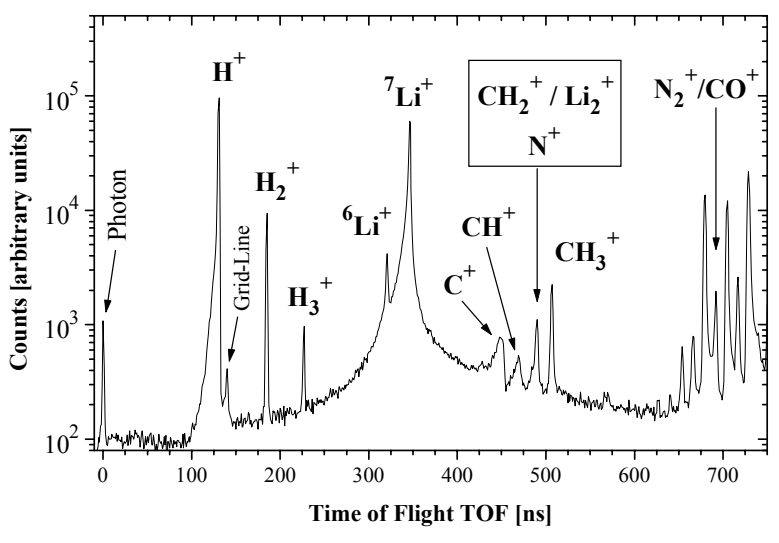

FIGURE 1. Secondary ion TOF-spectrum for $\mathrm{Ar}^{0}$ projectiles $\left(25 \mathrm{keV} / \mathrm{u}, \theta_{\mathrm{p}}=36^{\circ}\right)$ impacting a $\operatorname{LiF}(200 \AA)+\mathrm{Al}$ (2000 §) target.

The position and shape of these structures are independent of the bulk target material and are usually present in similar spectra of other collision systems. In particular, two symmetric distributions, around values of $\mathrm{x}=0$, correspond to $\mathrm{m}=14 \mathrm{u}^{7}\left(\mathrm{Li}_{2}{ }^{+}\right)$and $\mathrm{m}=15 \mathrm{u}$ $\left(\mathrm{CH}_{3}^{+}\right)$.

The measured X-TOF-distributions of ${ }^{7} \mathrm{Li}^{+}, \mathrm{C}^{+}$and $\mathrm{CH}^{+}$were transformed into velocity distributions and plotted in figures 3 and 4. In Fig. 3, as the calculations were performed for mass $7 \mathrm{u}$, there is a peak and a background contribution due to the lesser abundant isotope ${ }^{6} \mathrm{Li}^{+}$. At these low projectile velocities $(25$ $\mathrm{keV} / \mathrm{u}$ ) linear cascade processes are important, producing broad and roughly symmetric $\mathrm{Li}^{+}$ distributions. In contrast, the $\mathrm{C}^{+}$and $\mathrm{CH}^{+}$, (also $\mathrm{N}_{2}^{+}$, $\mathrm{CO}^{+}$, not shown) ion distributions in fig. 4 exhibit a

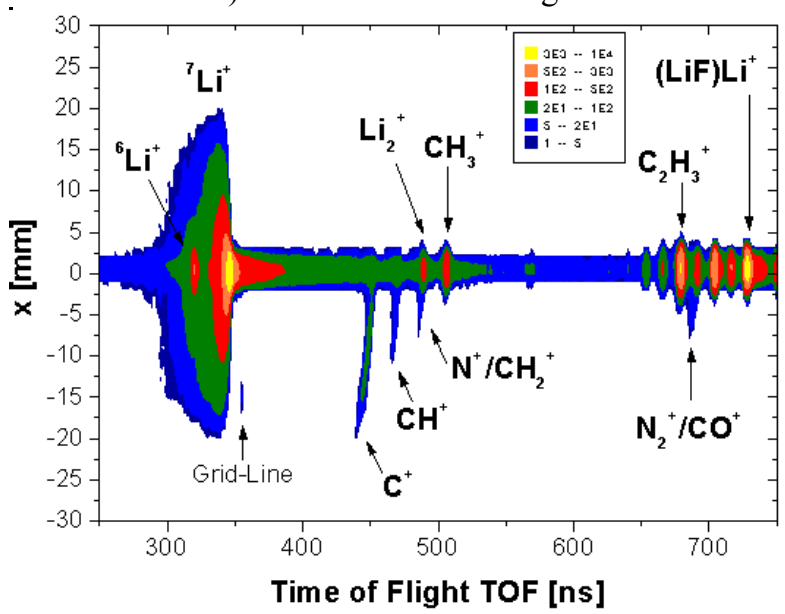

FIGURE 2. X-TOF ( $X Z$ plane projection) relative to the same data of Fig. 1, showing the contribution of the molecules containing $\mathrm{Li}$ and $\mathrm{C}$. The number of counts is coded by gray value 

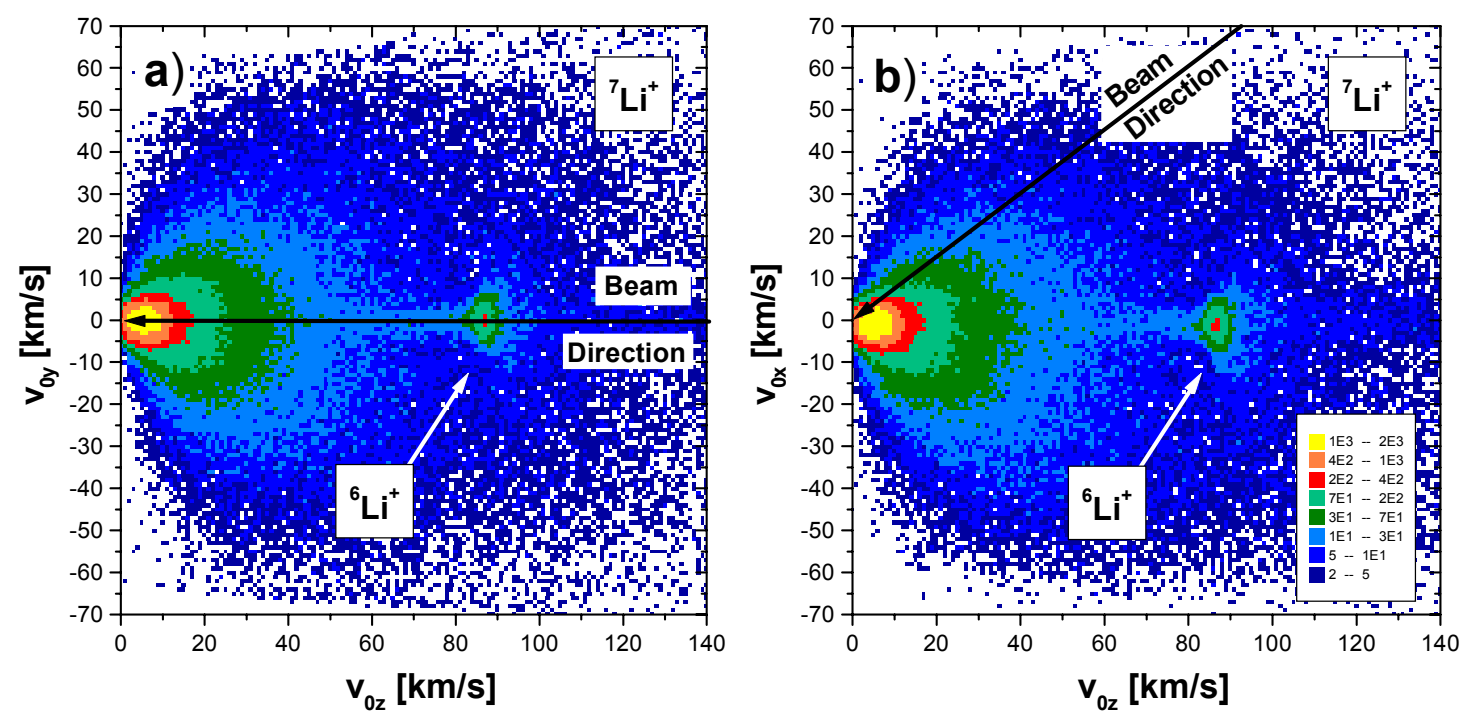

FIGURE 3. Secondary ions velocities in a) $\mathrm{YZ}$ plane and b) $\mathrm{XZ}$ plane. The velocities were calibrated for ${ }^{7} \mathrm{Li}^{+}$mass under the same experimental conditions as in Figs. 1 and 2. Due to high momentum transfer caused by binary collisions between the projectile and the target atoms, there is a background contribution of the isotope ${ }^{6} \mathrm{Li}^{+}$.

strong asymmetry in the scattering plane formed by the incident beam and the surface normal. These ions are emitted from the solid surface, with relatively high velocity : up to $\mathrm{v}_{0} \approx 80 \mathrm{~km} / \mathrm{s}(400 \mathrm{eV})$ for $\mathrm{C}^{+}$and $\mathrm{v}_{0} \approx$ $40 \mathrm{~km} / \mathrm{s}(100 \mathrm{eV})$ for $\mathrm{CH}^{+}$. Note, that the direction of emission is almost perpendicular to the beam direction.
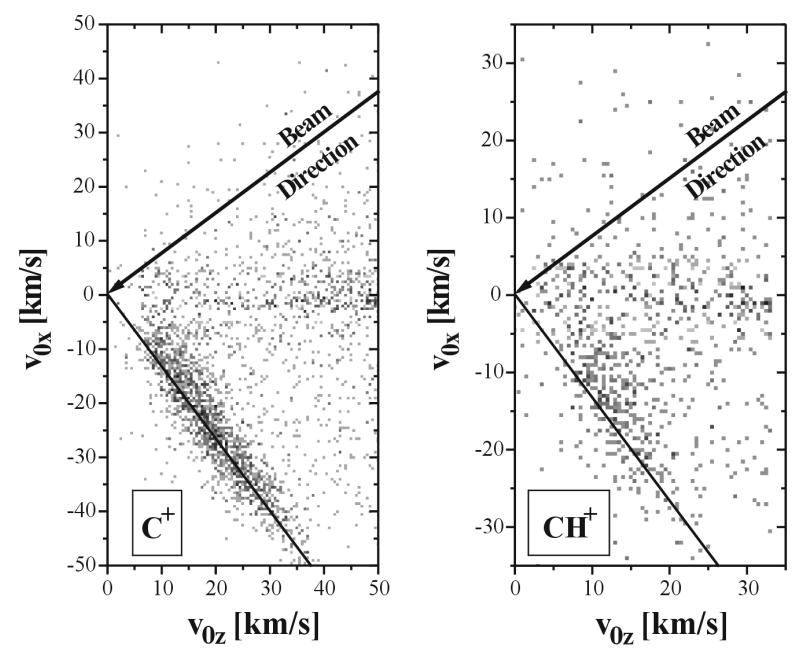

FIGURE 4. Velocity spectrum in XZ plane as in Fig. 3, but for ${ }^{12} \mathrm{C}^{+}$and $\mathrm{CH}^{+}$. The solid line drawn for negative $\mathrm{V}_{0 \mathrm{X}}$ values indicates the direction orthogonal to the beam.

\section{DISCUSSION}

These $\mathrm{C}_{\mathrm{n}} \mathrm{H}_{\mathrm{m}}{ }^{+}$needle-shaped structures in the spectra of Fig. 2 are clealy defined because these secondary particles originate from adsorbed layers on the target surface. They are emitted in a single collision, i.e. a binary collision between the projectile and e.g. a carbon atom respectively, resulting the secondary $\mathrm{C}^{+}$ ion, a common constituent of the molecular adsorbate on the target surface. It is a direct momentum transfer from the projectile to the target atom. A similar arrow shaped structure is observed in the $\mathrm{H}^{+}$secondary ion emission process. Its intensity is correlated with increasing nuclear stopping power $\mathrm{dE} / \mathrm{dx}_{\mathrm{n}}$ of the projectile and its direction with the projectile impact angle $\theta_{\mathrm{p}}$ [9]. Note, that e.g. the $\mathrm{C}^{+}$ions are emitted from the solid surface with maximum velocity of about $80 \mathrm{~km} / \mathrm{s}$ and under an angle of about $90^{\circ}$ with respect to the direction of the incident projectile (see fig. 5), which corresponds to the maximum of the elastic recoil cross section [10]. $\mathrm{CH}^{+}, \mathrm{CH}_{2}^{+}$and $\mathrm{N}_{2}^{+}$show a similar emission structure. It is indeed surprising that these three molecular ions can survive such a violent binary collision with the projectile.

The high velocity molecular emission however is not observed for $\mathrm{H}_{2}^{+}, \mathrm{H}_{3}{ }^{+}, \mathrm{CH}_{3}{ }^{+}$secondary ions (see Fig. 2) or for molecules with more than 3 atoms. The hydrogen cluster ions, $\mathrm{CH}_{3}{ }^{+}$and hydrocarbons of higher masses are therefore more likely to dissociate than to be emitted intact after a binary collision with the projectile. Molecular binding energy and an upper number of molecular constituents may be the relevant parameters that allow a surface molecule, or its molecular fragments, to survive the impact of fast projectiles. Besides a broad velocity distribution, emission of molecules with many constituents are 
expected to be more symmetric around the Z-axis than the mentioned needle-shaped structure molecules.

The target atomic ions do not show such a pronounced structure. As mentioned, at low projectile energy, the $\mathrm{v}_{0 \mathrm{y}}-\mathrm{v}_{0 \mathrm{z}}$-distribution are symmetric , and broad, without a sharp structure. A small, but visible, asymmetry between positive and negative $\mathrm{x}$ values (in the $\mathrm{XZ}$ scattering plane) indicates that the emitted $\mathrm{Li}^{+}$ions still remember somewhat of the direction of the incoming projectile. The broad $\mathrm{Li}^{+}$distribution indicates that bulk ions cannot be emitted in one single collision with projectile but rather only after a sequence of collisions with its neighbors, i.e. the atoms of the substrate or the atoms of the surface adsorbates.

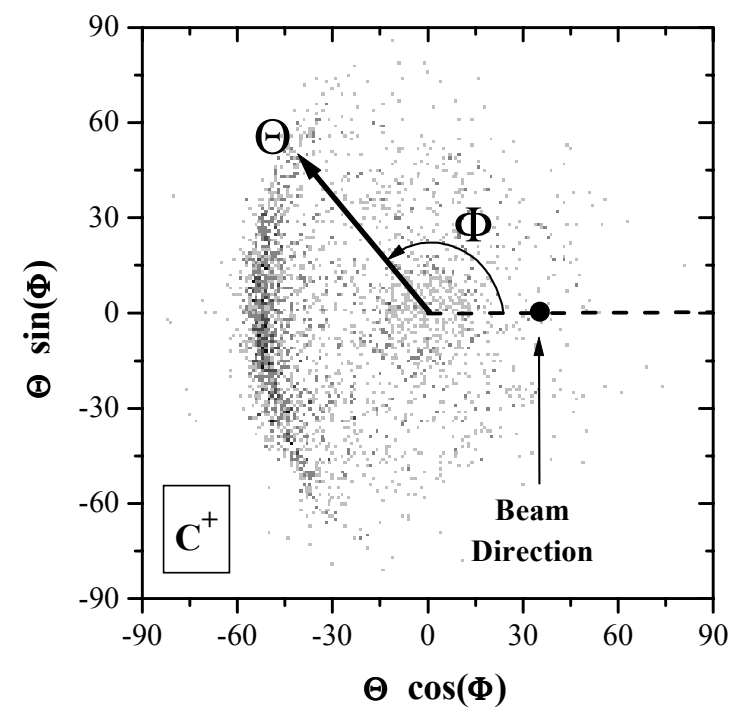

FIGURE 5. Orthographic projection of the angular distribution relative to Fig. $4 \mathrm{a}$. $\Theta$ is the angle with $\mathrm{Z}$ axis and $\Phi$ is the angle with the $\mathrm{XZ}$ plane. In this plot, for each event, the emission angle $\Theta$ is the distance to the center $(0,0)$ of the distribution. The beam direction is, in this case, $\Theta=36^{\circ}$ and $\Phi=0$.

\section{CONCLUSION}

The presented experimental method provides a powerful technique to access the understanding of basic interaction mechanisms of projectiles with solids and its surfaces. Such type of analysis is useful for material and surface science by identifying the origin of secondary ions from the surface and by distinguishing single- and multiple-collision processes in the target substrate. The method is applied to the analysis of molecular secondary ions emitted with high velocity during $\mathrm{MeV}$ bombardment of the target. The $\mathrm{Li}^{+}$ions from the bulk substrate shows broad emission velocity distributions, a signature of emission by a multiple collision process. Moreover, the initial velocity distributions for atomic $\mathrm{C}^{+}$and for molecular adsorbate fragments such as $\mathrm{CH}^{+}$and $\mathrm{N}_{2}^{+} / \mathrm{CO}_{2}^{+}$show that the secondary particles are emitted close to a plane perpendicular to the beam direction, with a maximum cross section in the beam incidence plane. It is concluded that the emission process is due to projectile-molecule binary collisions, with large impact parameter, producing molecular fragments formed with small number of constituents.

\section{ACKNOWLEDGMENTS}

We gratefully acknowledge support by DAADBonn, VW-Stiftung, Willkomm-Stiftung-Frankfurt a. M. Germany and CAPES/PROBRAL Brazil. K.O.G also thanks DFG-Bonn and L.S.F., V.M.C. and E.F.S. thanks the Brazilian agencies CNPq and FAPERJ for partial support.

\section{REFERENCES}

1. D.P. Woodruff and T.A. Delchar , Modern Techniques of Surface Science, Ed. By Cambridge Solid State Science Series, 1986.

2. B.U.R. Sundqvist, A. Hedin, P. Hakasson, M. Salehpour, G. Säve and R.E. Johnson, Nucl. Instrum. Methods B 14 (1986) 429 .

3. Review by B.U.R. Sundqvist, p.59-93, Collision Processes of Ion, Positron, Electron and Photon Beams with Matter, Ed. By A. C. Souza, E.F. da Silveira, J.C. Nogueira, M. Nascimento and D.P. Almeida, World Scientific, 1992.

4. C.V. Barros Leite, E.F. da Silveira, J.M.F. Jeronymo, R.R. Pinho, G.B. Baptista, E.A. Schweikert and M.A. Park. Phys. Review B45 (1992) 12218.

5. R.E. Johnson , Int. J. Mas Spectrom and Ion Processes, 78 (1987) 357.

6. R. R. Lucchese, J. Chem. Phys. 86 (1987) 443.

7. R.L. Betts, E.F. da Silveira and E.A. Schweikert. Int. J. Mass Spectrom. 145 (1995) 9.

8. T. Jalowy, R. Neugebauer, M. Hattass, J. Fiol, F. Afaneh, J.A.M. Pereira, E. F. da Silveira, H. Schmidt-Böcking and K.O. Groeneveld, Nuclear Instr. and Meth. in Phys. Res. Sect. B 193 (2002) 792-796.

9. T. Jalowy, R. Neugebauer, L.S. Farenzena, E. F. da Silveira, H. Schmidt-Böcking and K.O. Groeneveld, in preparation.

10. J.C. Barbour, B.L. Doyle, Handbook of Modern Ion Beam Materials, edited by J.R. Tesmer, N.Nastasi (1995) 83. 